Article

\title{
First-Principles Investigation of Phase Stability, Electronic Structure and Optical Properties of MgZnO Monolayer
}

\author{
Changlong Tan ${ }^{1, *}$, Dan Sun ${ }^{1}$, Xiaohua Tian ${ }^{1}$ and Yuewu Huang ${ }^{2}$ \\ 1 College of Applied Science, Harbin University of Science and Technology, Harbin 150080, China; \\ wyysundan@163.com (D.S.); xiaohuatian@hrbust.edu.cn (X.T.) \\ 2 School of Materials Science and Engineering, Harbin Institute of Technology, Harbin 150001, China; \\ wuyuehuang@gmail.com \\ * Correspondence: changlongtan@hrbust.edu.cn; Tel.: +86-451-8639-0728
}

Academic Editor: Martin O. Steinhauser

Received: 11 August 2016; Accepted: 25 October 2016; Published: 27 October 2016

\begin{abstract}
MgZnO}$ bulk has attracted much attention as candidates for application in optoelectronic devices in the blue and ultraviolet region. However, there has been no reported study regarding two-dimensional $\mathrm{MgZnO}$ monolayer in spite of its unique properties due to quantum confinement effect. Here, using density functional theory calculations, we investigated the phase stability, electronic structure and optical properties of $\mathrm{Mg}_{x} \mathrm{Zn}_{1-x} \mathrm{O}$ monolayer with $\mathrm{Mg}$ concentration $x$ range from 0 to 1. Our calculations show that $\mathrm{MgZnO}$ monolayer remains the graphene-like structure with various $\mathrm{Mg}$ concentrations. The phase segregation occurring in bulk systems has not been observed in the monolayer due to size effect, which is advantageous for application. Moreover, $\mathrm{MgZnO}$ monolayer exhibits interesting tuning of electronic structure and optical properties with $\mathrm{Mg}$ concentration. The band gap increases with increasing $\mathrm{Mg}$ concentration. More interestingly, a direct to indirect band gap transition is observed for $\mathrm{MgZnO}$ monolayer when $\mathrm{Mg}$ concentration is higher than 75 at \%. We also predict that Mg doping leads to a blue shift of the optical absorption peaks. Our results may provide guidance for designing the growth process and potential application of $\mathrm{MgZnO}$ monolayer.
\end{abstract}

Keywords: MgZnO monolayer; phase stability; electronic structure; optical property

\section{Introduction}

Two-dimensional (2D) materials present rather unique and exceptional properties due to the restrictions of size in one dimension and emerging 2D confinement effects. Moreover, they are easier to fabricate into complex structures than in 1D state. The discovery of 2D graphene has led to the intense interest in other 2D materials with novel properties [1]. ZnO displays a direct and wide band gap, large exciton binding energy, and strong piezoelectricity, and is widely applied in blue/UV light-emitting diodes, photocatalysts, sensors, and so on [2-5]. As the allotrope of superior bulk $\mathrm{ZnO}$, the 2D $\mathrm{ZnO}$ sheet logically triggers the scientists' interest [6-16]. The $2 \mathrm{D} \mathrm{ZnO}$ sheet was firstly theoretically predicted by Freeman, where $\mathrm{Zn}$ and $\mathrm{O}$ atoms are arranged in planar sheet like in the hexagonal $\mathrm{BN}$ monolayer [6]. Experimentally, Tushce et al. were the first to synthesize two-monolayer-thick $\mathrm{ZnO}(0001)$ films on $\mathrm{Ag}(111)$ substrate, which provided a direct evidence for the presence of planar $\mathrm{ZnO}$ sheets [7]. Very recently, in situ observations of free-standing graphene-like $\mathrm{ZnO}$ monolayer has been reported [9]. These provide a platform to design $\mathrm{ZnO}$ monolayer-based new functional devices.

Band gap modulation in $\mathrm{ZnO}$ monolayer is very important for designing its optoelectronic devices. To date, however, there is few reported study regarding this aspect [16]. For $\mathrm{ZnO}$ bulk and thin films, 
previous studies indicate that modulation of band gap could be realized through the doping of a metal element in $\mathrm{ZnO}$. Among various dopants, $\mathrm{Mg}$ can be easily doped in $\mathrm{ZnO}$ for its similar radius and electronic shell to $\mathrm{Zn}$ atom. Many properties of $\mathrm{ZnO}$ can be modulated by doping of Mg. For example, $\mathrm{Mg}$ doping can increase the band gap, which is critical to the application in blue and ultraviolet region [17]. Therefore, $\mathrm{MgZnO}$ is an important element for the realization of band gap engineering to create barrier layers and quantum wells in ZnO-based optoelectronic devices. Recently, many researchers devoted great efforts to the study of the fundamental physical properties of $\mathrm{MgZnO}$ alloys [18-21]. Many theoretical studies and experimental researches on Mg-doped $\mathrm{ZnO}$ have achieved a reasonable understanding of the action of doping on crystalline and structures, as well as their optical and electronic properties [22,23]. Moreover, considerable effort has been devoted for the fabrication and characterization of $\mathrm{ZnO} / \mathrm{MgZnO}$ multiple quantum wells as well as superlattice [24] by molecular beam expitaxy [25], metal-organic vapor-phase epitaxy [26], and pulsed laser deposition [27]. Up to now, most of the existing research on $\mathrm{MgZnO}$ focused on bulk and thin films forms [28-36]. To the best of our knowledge, there have not been any previous investigations on the $\mathrm{MgZnO}$ monolayer in spite of its unique structure and properties different from their bulk counterpart. Moreover, it is worth noting that in the case of bulk material, the phase segregation between $\mathrm{ZnO}$ and $\mathrm{MgO}$ was observed for $\mathrm{Mg}$ concentration $\mathrm{x}>0.36$ due to the different crystal structures and large lattice mismatch between $\mathrm{ZnO}$ and $\mathrm{MgO}$ [37]. Thus, the high $\mathrm{Mg}$ content single phase wurtzite $\mathrm{MgZnO}$ is difficult to be obtained. $\mathrm{ZnO}$ bulk is wurtzite structure while 2D $\mathrm{ZnO}$ monolayer exhibits graphene-like structure. Since dimensionality is a known factor deciding structure and properties of material, it is of fundamental interest to investigate whether phase segregation can occur in these 2D materials and further to find their phase stability phenomena, which may be different from those in bulk materials.

Therefore, the present study is dedicated to investigate the phase stability, electronic structure, and optical properties of $\mathrm{Mg}_{x} \mathrm{Zn}_{1-x} \mathrm{O}(x=0.0625,0.125,0.25,0.5,0.75,1)$ monolayer with $\mathrm{Mg}$ concentration $x$ range from 0 to 1 by means of first principles calculation. Our results show that different from bulk system, the phase segregation has not been observed in the monolayer due to size effect. Moreover, $\mathrm{MgZnO}$ monolayer exhibits interesting tuning of the band gap and optical properties with $\mathrm{Mg}$ concentration. Our results may provide guidance for designing the growth process and potential application of $\mathrm{MgZnO}$ monolayer.

\section{Calculational Methods}

First-principles calculations are based on the density functional theory and the plane wave method as implemented in the CASTEP code [38]. The interaction between ions and electron is described by ultrasoft pseudopotentials [39]. The cutoff energy for the plane wave basis set is set to $400 \mathrm{eV}$. The Monkhorst-Pack grid of $4 \times 4 \times 1$ is adopted for the brillouin zone integration. The calculations are carried out with spin-polarization and each system is fully relaxed. In all calculations, the convergence criteria for changes in energy, maximum force, and maximum displacement are $1.0 \times 10^{-5} \mathrm{eV} / \mathrm{atom}$, $0.03 \mathrm{eV} / \AA$ and $0.001 \AA$, respectively. The $\mathrm{MgZnO}$ monolayer systems are modeled using a periodic boundary condition applied in two directions by the supercell method. Along the direction perpendicular to the $\mathrm{MgZnO}$ monolayer, $15 \AA$ of vacuum is included to avoid interaction of periodic images. The models of $4 \times 4$ supercell for $\mathrm{ZnO}$ monolayer with one or two $\mathrm{Zn}$ atoms replaced by $\mathrm{Mg}$ atoms correspond to 6.25 and 12.5 at \% of $\mathrm{Mg}$ in $\mathrm{MgZnO}$ monolayer, respectively. The models of $2 \times 2$ supercell for $\mathrm{ZnO}$ monolayer with one to four $\mathrm{Zn}$ atoms replaced by $\mathrm{Mg}$ atoms correspond to 25 , 50, 75, and 100 at \% of Mg in MgZnO monolayer, respectively. Standard DFT calculation generally underestimates the energy gap of $\mathrm{ZnO}$ system. In our previous study [16], we used the DFT+ $U$ method to overcome the band-gap problem, in which the Hubbard parameter of $U$ is added to both $\mathrm{Zn} 3 d$ and O $2 p$ orbits $\left(U_{\mathrm{d}, \mathrm{Zn}}=10 \mathrm{eV}\right.$ and $\left.U_{\mathrm{p}, \mathrm{O}}=7 \mathrm{eV}\right)$. The calculated band gap of $3.36 \mathrm{eV}$ for $\mathrm{ZnO}$ bulk is in good agreement with experimental results [2]. Therefore, taking the same $U$ parameters, the electronic structure and optical property of $\mathrm{MgZnO}$ monolayer have been calculated in this work. 


\section{Results and Discussion}

\subsection{The Pristine ZnO Monolayer}

To investigate the properties of $\mathrm{MgZnO}$ monolayer, the structural and electronic properties of pristine $\mathrm{ZnO}$ monolayer are necessary to be calculated. Starting from a structure cut from the $\mathrm{ZnO}$ wutrztie crystal and terminated with the (0001) polar surface, atomic relaxations from the DFT calculations indicate that $\mathrm{ZnO}$ monolayer stabilizes in a hexagonal BN structure, as shown in Figure 1a. Unlike fourfold coordinate $\mathrm{Zn}$ and $\mathrm{O}$ atoms in the bulk wurtzite structure, each atom in the monolayer is three-fold coordinated, consistent with earlier theoretical predication. The calculated $\mathrm{Zn}-\mathrm{O}$ bond length in monolayer $\mathrm{ZnO}$ is $1.91 \AA$, which is lower than the corresponding bond length in bulk $\mathrm{ZnO}$ of $2.01 \AA$. Regarding of electronic structure, the calculated band structure and density of states of $\mathrm{ZnO}$ monolayer are shown in Figure $1 \mathrm{~b}, \mathrm{c}$, respectively. The band structure indicates that the pristine $\mathrm{ZnO}$ monolayer is a nonmagnetic semiconductor and retains the direct band gap characteristic of their wurtzite bulk. Our DFT+U calculations give a band gap of $4.08 \mathrm{eV}$, which is more close to the experimental value of $4.50 \mathrm{eV}$ than those obtained in previous DFT calculations $[10,40,41]$. The improvement for the prediction of band gap of $\mathrm{ZnO}$ monolayer in present work than previous studies is attributed to that $U$ values are included for both $\mathrm{Zn} 3 d$ and $\mathrm{O} 2 p$ orbits. Moreover, it should be pointed out that the band gap of pristine $\mathrm{ZnO}$ monolayer is enlarged with respect to the bulk $\mathrm{ZnO}$ band gap (3.37 eV). This phenomenon is confirmed due to quantum confinement effects from both theoretical and experimental aspects [42,43]. Moreover, from density of states (DOS) of pristine ZnO monolayer shown in Figure 1c, it can be seen that the valence bands near the Fermi level are dominated by $\mathrm{O} 2 p$ states and the conduction bands are mainly ascribed to the states of $\mathrm{O} 2 p$ and $\mathrm{Zn} 4 s$ states.
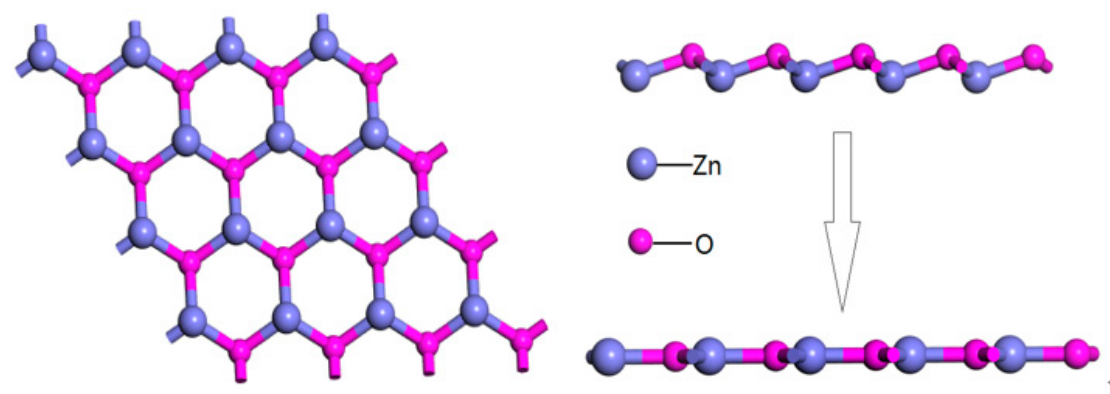

(a)

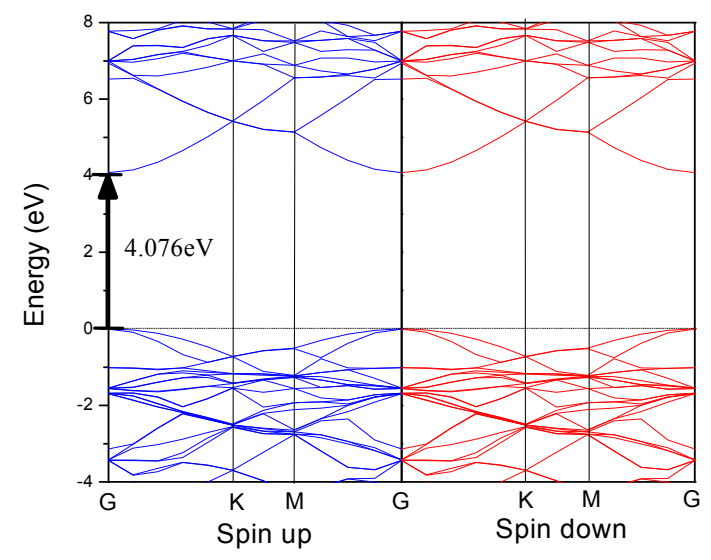

(b)

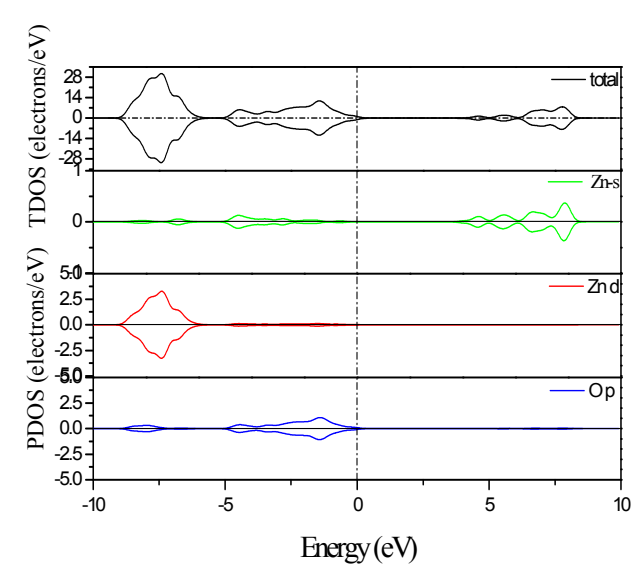

(c)

Figure 1. The structural and electronic properties of pristine $\mathrm{ZnO}$ monolayer: (a) relaxed structure; (b) band structure; (c) DOS. 


\subsection{Phase Stability of $\mathrm{MgZnO}$ Monolayer}

It is generally regarded that in the case of $\mathrm{MgZnO}$ bulk material, the phase segregation between $\mathrm{ZnO}$ and $\mathrm{MgO}$ was observed for $\mathrm{Mg}$ concentration $x>0.36$ due to the different crystal structures and large lattice mismatch. This phase segregation significantly limits the application of $\mathrm{MgZnO}$ material. Considering that dimensionality is a known factor deciding structure and properties of material, it is of fundamental interest to investigate if phase segregation can occur in $2 \mathrm{D} \mathrm{MgZnO}$ monolayer. In order to find their phase stability phenomena, the formation energies $(\Delta E)$ of $\mathrm{MgZnO}$ monolayer with various $\mathrm{Mg}$ concentrations are calculated, as shown in Table 1 . The formation energy is defined as follows: $\Delta E(x)=E\left(\mathrm{Mg}_{x} \mathrm{Zn}_{1-x} \mathrm{O}\right)-\{x E(\mathrm{MgO})+(1-x) E(\mathrm{ZnO})\}$, where $E\left(\mathrm{Mg}_{x} \mathrm{Zn}_{1-x} \mathrm{O}\right), E(\mathrm{MgO})$, and $E(\mathrm{ZnO})$ are the total energies per supercell of the relaxed monolayer, respectively [44,45]. The negative formation energy means the formation of the monolayer is thermodynamically favorable from the constituents at their stable bulk structures. In terms of all $\mathrm{Mg}$ concentration, their formation energies are negative. So we concluded from the formation energies calculations that $\mathrm{MgZnO}$ monolayer can possibly be synthesized by the experimental methods, and this $\mathrm{MgZnO}$ monolayer should be thermodynamically stable against the phase separation in the corresponding bulk material. For the bulk system, pure ZnO bulk prefers the wurtzite crystal structure, while MgO bulk adopts the cubic rocksalt structure. Therefore, in the case of $\mathrm{MgZnO}$ bulk material, the phase segregation between $\mathrm{ZnO}$ and $\mathrm{MgO}$ was observed due to the different crystal structures and large lattice mismatch. In contrast to bulk system, our formation energies calculations show that $\mathrm{MgZnO}$ monolayer including both $\mathrm{ZnO}$ and $\mathrm{MgO}$ monolayer can keep hexagonal BN structure (graphene-like structure). Indeed, our calculations show that the formation energy of $\mathrm{MgO}$ monolayer is far more favorable than other cases. Moreover, the phase stability of $\mathrm{MgO}$ monolayer has been verified by other investigations as well $[46,47]$. Both our studies and previous investigations demonstrate that $\mathrm{ZnO}$ monolayer and $\mathrm{MgO}$ monolayer exhibit the same hexagonal BN structure. We inferred that this is the internal reason why the phase segregation did not occur in the monolayer. These results demonstrate that $2 \mathrm{D} \mathrm{ZnO}$ materials exhibit significantly different phase stability phenomena compared to their bulk counterparts and would be useful for designing the growth process and application of $\mathrm{MgZnO}$ monolayer.

Table 1. The structural parameters and formation energies for $\mathrm{MgZnO}$ monolayer.

\begin{tabular}{cccccc}
\hline \multirow{2}{*}{ Composition } & \multicolumn{2}{c}{ Bond Length $(\mathbf{n m})$} & \multicolumn{2}{c}{ Bond Angle $\left(^{\circ}\right)$} & $\Delta E(\mathbf{e V})$ \\
\cline { 2 - 6 } & $\boldsymbol{d}_{\mathrm{Zn}-\mathrm{O}}$ & $\boldsymbol{d}_{\boldsymbol{M g}-\mathrm{O}}$ & $\boldsymbol{\theta}_{\boldsymbol{O}-\mathrm{Zn}-\mathrm{O}}$ & $\boldsymbol{\theta}_{\boldsymbol{O}-\mathbf{M g}-\mathrm{O}}$ & \\
\hline 0 at $\% \mathrm{Mg}$ & 0.1910 & - & 120 & - & 0 \\
6.25 at $\% \mathrm{Mg}$ & 0.1906 & 0.1897 & 119.37 & 120 & -2.7302 \\
12.5 at $\% \mathrm{Mg}$ & 0.1910 & 0.1906 & 117.79 & 118.63 & -5.4635 \\
25 at $\% \mathrm{Mg}$ & 0.1911 & 0.1902 & 119.37 & 119.91 & -0.6607 \\
50 at $\% \mathrm{Mg}$ & 0.1925 & 0.1899 & 119.061 & 119.19 & -1.4450 \\
75 at $\% \mathrm{Mg}$ & 0.1912 & 0.1912 & - & 119.59 & -2.3109 \\
100 at $\% \mathrm{Mg}$ & - & 0.1881 & - & 120 & 0 \\
\hline
\end{tabular}

Furthermore, the structural parameters for $\mathrm{MgZnO}$ monolayer with various $\mathrm{Mg}$ concentrations after the structural optimizations have been listed in Table 1. The relaxed structures of $\mathrm{MgZnO}$ monolayer are shown in Figure 2. It can be seen that the calculated bond lengths between $\mathrm{Mg}$ atoms and the nearest-neighbor $\mathrm{O}$ atoms are slightly smaller than that of the $\mathrm{Zn}-\mathrm{O}$ bond length. The calculated $\mathrm{Mg}-\mathrm{O}$ bond length different from the $\mathrm{Zn}-\mathrm{O}$ bond length is due to the different ionic radius between $\mathrm{Zn}$ and $\mathrm{Mg}$ atoms. The $\mathrm{O}-\mathrm{Mg}-\mathrm{O}$ bond angle is approximately $119^{\circ}$. Considering the $\mathrm{O}-\mathrm{Zn}-\mathrm{O}$ bond angle is $120^{\circ}$ in the pristine $\mathrm{ZnO}$ monolayer, it can be known that $\mathrm{Mg}$ doping distorts the bond angle slightly. The above results show that all the lattice structure $\mathrm{MgZnO}$ monolayer with different $\mathrm{Mg}$ concentration after geometric optimization still keeps graphene-like structure as that of pristine $\mathrm{ZnO}$ monolayer. 


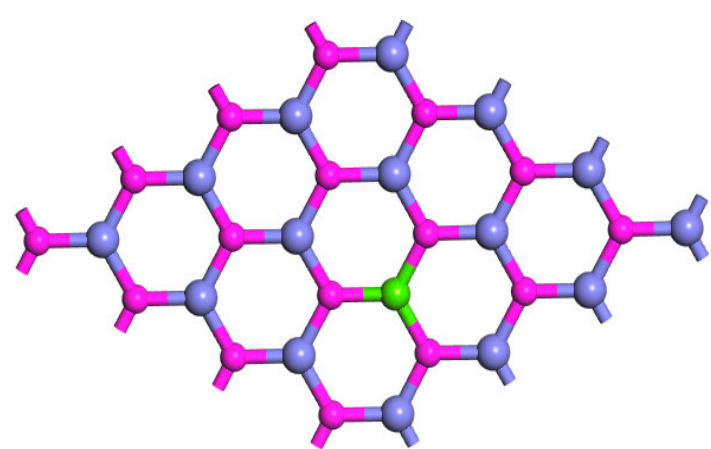

(a)

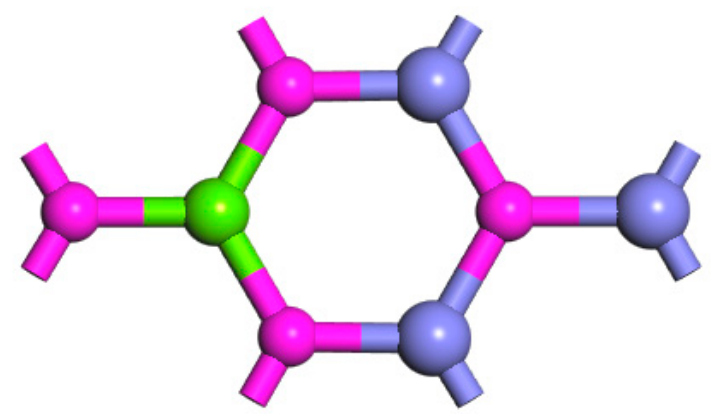

(c)

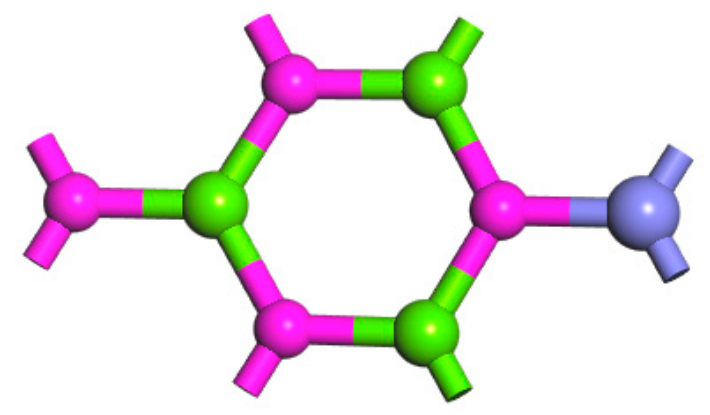

(e)

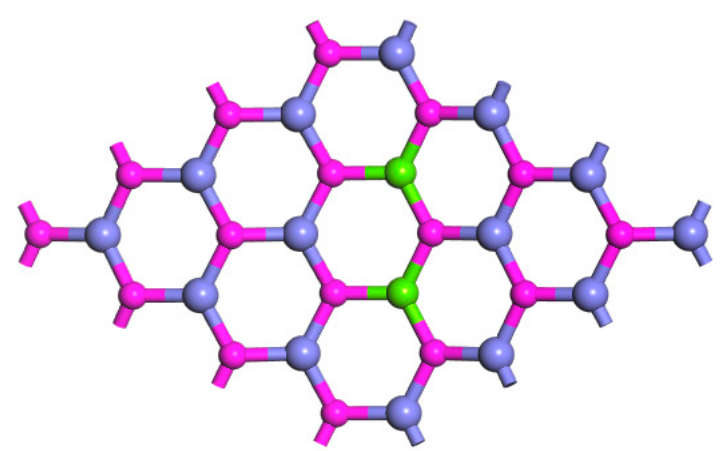

(b)

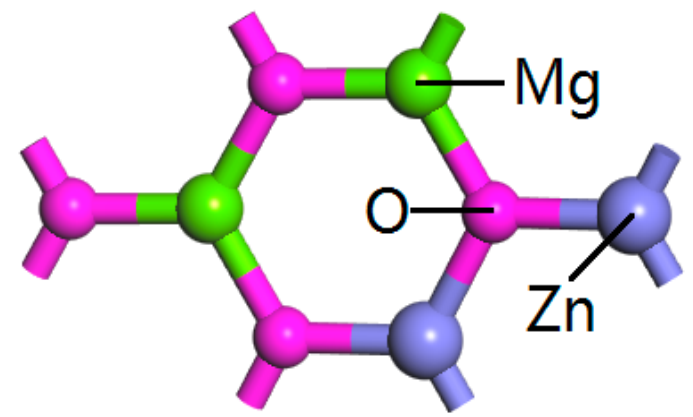

(d)

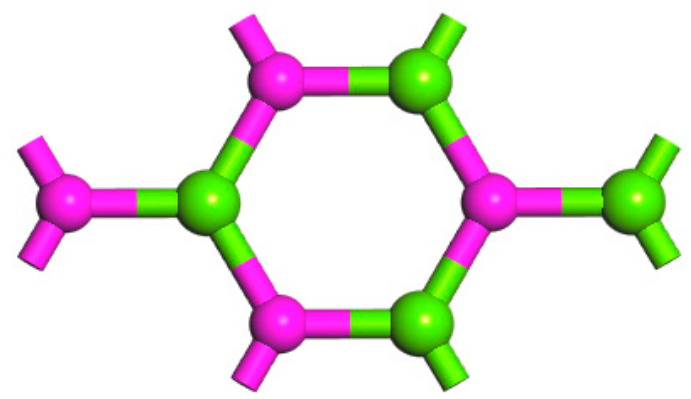

(f)

Figure 2. The relaxed structure of $\mathrm{Mg}_{x} \mathrm{Zn}_{1-x} \mathrm{O}$ monolayer (a) $x=0.0625$; (b) $x=0.125$; (c) $x=0.25$; (d) $x=0.5 ;$ (e) $x=0.75 ;$ (f) $x=1$.

\subsection{Electronic Structure of $\mathrm{MgZnO}$ Monolayer}

Figure 3 shows the band structure of $\mathrm{MgZnO}$ monolayer with various $\mathrm{Mg}$ concentrations. It is found that the valence band maximum in $\mathrm{MgZnO}$ monolayer is always at the Fermi level and it has no obvious shift with $\mathrm{Mg}$ doping. However, the bottom of the conduction band shifts to a higher energy side with increasing $\mathrm{Mg}$ concentration. The bottom of the conduction band mainly consists of $\mathrm{Zn} 4 \mathrm{~s}$ states. When the Mg concentration increases, the $\mathrm{Zn} 4 s$ states at the bottom of conduction band become weaker, resulting in the shift of conduction band and band gap widening. We summarize the results for band gap versus $\mathrm{Mg}$ concentration for $\mathrm{MgZnO}$ monolayer, as shown in Figure 4. Overall, there is a monotonous increase of band gaps with increasing Mg concentration, which is similar to the previous study of $\mathrm{MgZnO}$ bulk. Particularly, a direct to indirect band gap transition is observed for $\mathrm{MgZnO}$ monolayer when $\mathrm{Mg}$ concentration is higher than 75 at \%. In the case of $\mathrm{Mg}$ concentration lower than 75 at $\%, \mathrm{MgZnO}$ monolayer remains a direct band gap semiconductor with both the top of valence band and the bottom of the conduction band located the $G$ point, which is similar to that of pristine $\mathrm{ZnO}$ monolayer. However, when $\mathrm{Mg}$ concentration is higher than 75 at \%, the band structure of $\mathrm{MgZnO}$ monolayer transforms to indirect band with the valence band maximum (VBM) and the conduction 
band minimum (CBM) located at $K$ and $G$ symmetry points, respectively. This study for $\mathrm{MgZnO}$ monolayer has provided a simple route to systems in which band gap engineering from a direct to and indirect band gap semiconductors is possible. Moreover, it is well known that the energy levels close to the Fermi level generally play main roles in the electrical and optical properties of materials, so we focus the VBM and CBM. As shown in Figure 3, with increasing Mg concentration, the shape of the bottom conduction band gradually becomes more parabolic (or spherical) with increasing Mg content and the width of the top valence band is narrowed gradually. The shape of bottom conduction band is usually related to the effective mass of electrons. The change of bottom conduction band shape would affect the effective mass of electrons. So the electrical properties of $\mathrm{MgZnO}$ monolayer may be tuned by $\mathrm{Mg}$ concentration.

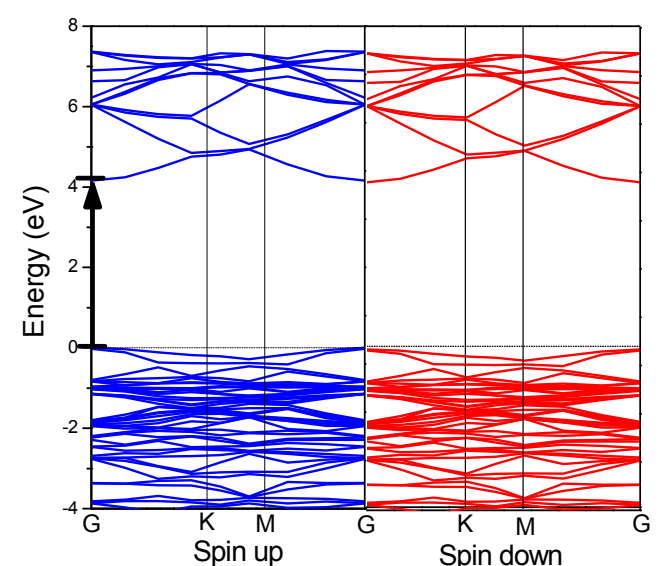

(a)

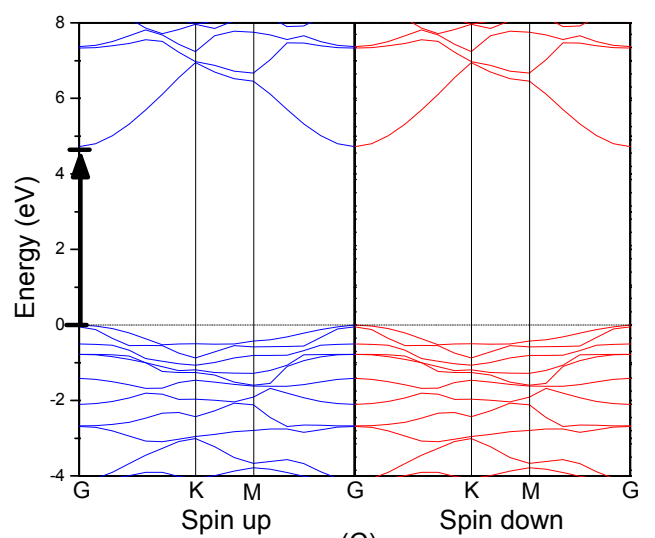

(C)

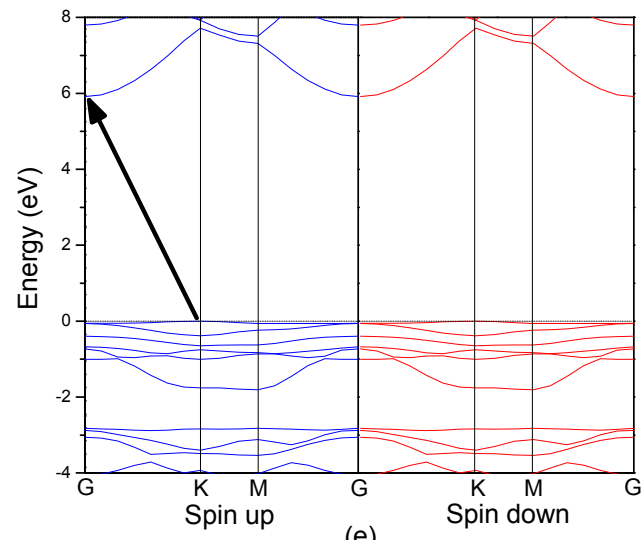

(e)

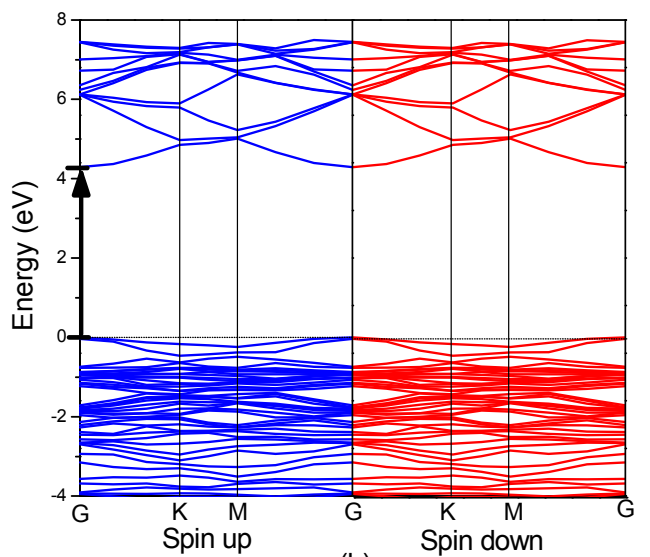

(b)

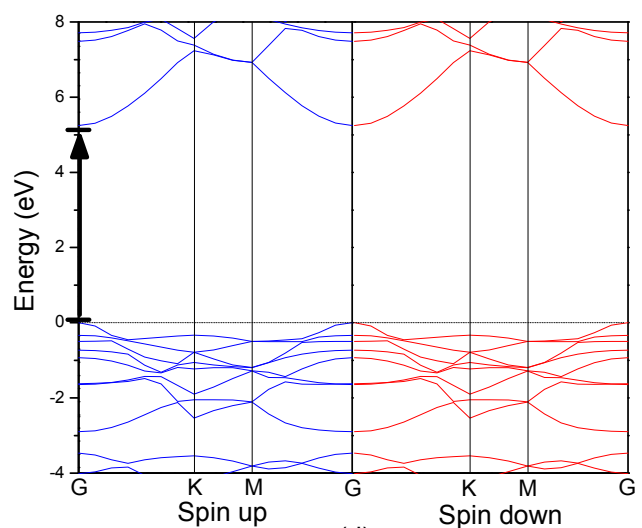

(d)

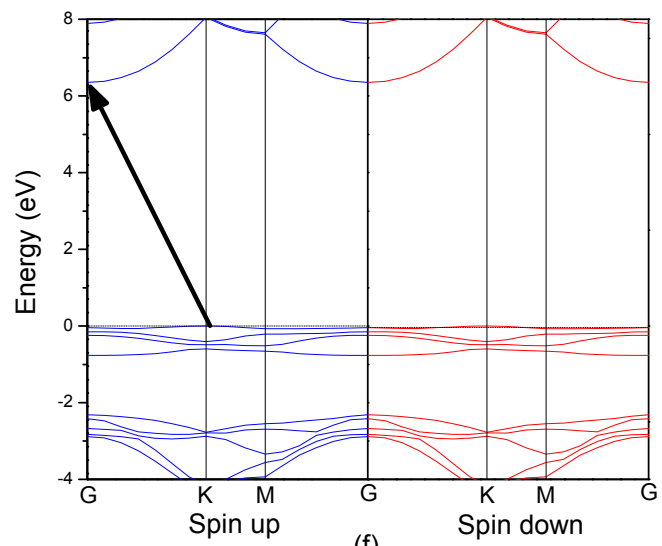

(f)

Figure 3. The band structures of $\mathrm{Mg}_{x} \mathrm{Zn}_{1-x} \mathrm{O}$ monolayer (a) $x=0.0625$; (b) $x=0.125$; (c) $x=0.25$; (d) $x=0.5 ;$ (e) $x=0.75 ;$ (f) $x=1$. 


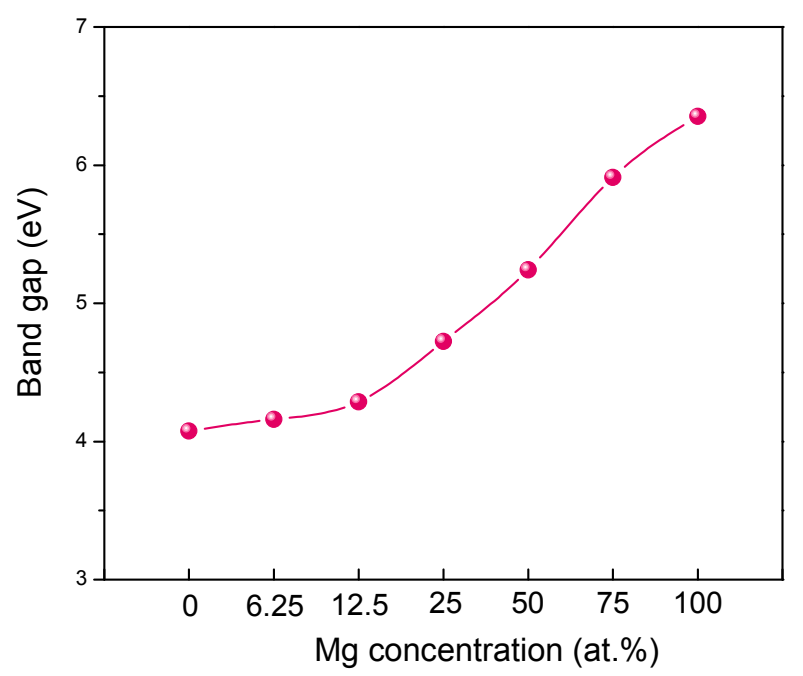

Figure 4. The band gap of $\mathrm{MgZnO}$ monolayer versus $\mathrm{Mg}$ concentration.

The density of states (DOS) is an important part of the electronic property of semiconductor materials. Furthermore, the total DOS (TDOS) and partial DOS (PDOS) of MgZnO monolayer are presented in the Figure 5. It can be seen that the total DOS of $\mathrm{MgZnO}$ monolayer is similar to those of pristine $\mathrm{ZnO}$ monolayer. The valence bands come mainly from the $\mathrm{O} 2 p$ and $\mathrm{Zn} 3 d$ states, whereas the conduction bands originating from the $\mathrm{Zn} 4 s$ and $\mathrm{Mg} 2 p$ states. It is worth noting that $\mathrm{Mg} 2 p$ states are higher than that of $\mathrm{Zn} 4 s$ states in energy position. With increasing $\mathrm{Mg}$ concentration, the CBM determined by $\mathrm{Zn} 4 s$ and $\mathrm{Mg} 2 p$ states shifts to high energy range obviously while the VBM determined by $\mathrm{O} 2 p$ states nearly remains unchanged. This is the main reason for the increase of the band gap in the $\mathrm{MgZnO}$ monolayer with increasing $\mathrm{Mg}$ concentration. Moreover, the $\mathrm{Zn} 3 d$ states decreased slightly with increasing $\mathrm{Mg}$ concentration in the $\mathrm{MgZnO}$ monolayer. It is well known that the $\mathrm{Mg}$ has no occupied $d$ orbit, thus $\mathrm{Mg}$ incorporation decrease the hybridization between the $\mathrm{Zn} 3 d$ and $\mathrm{O} 2 p$ states. Moreover, it is found that the $\mathrm{O} 2 p$ and $\mathrm{Zn} 3 d$ states become increasingly localized with a narrower band width with increasing $\mathrm{Mg}$ concentrations. The enhanced localization in the $\mathrm{O} 2 p$ and $\mathrm{Zn} 3 d$ states indicates more ionic character in $\mathrm{MgZnO}$ monolayer, which also benefits the increase of the band gap.
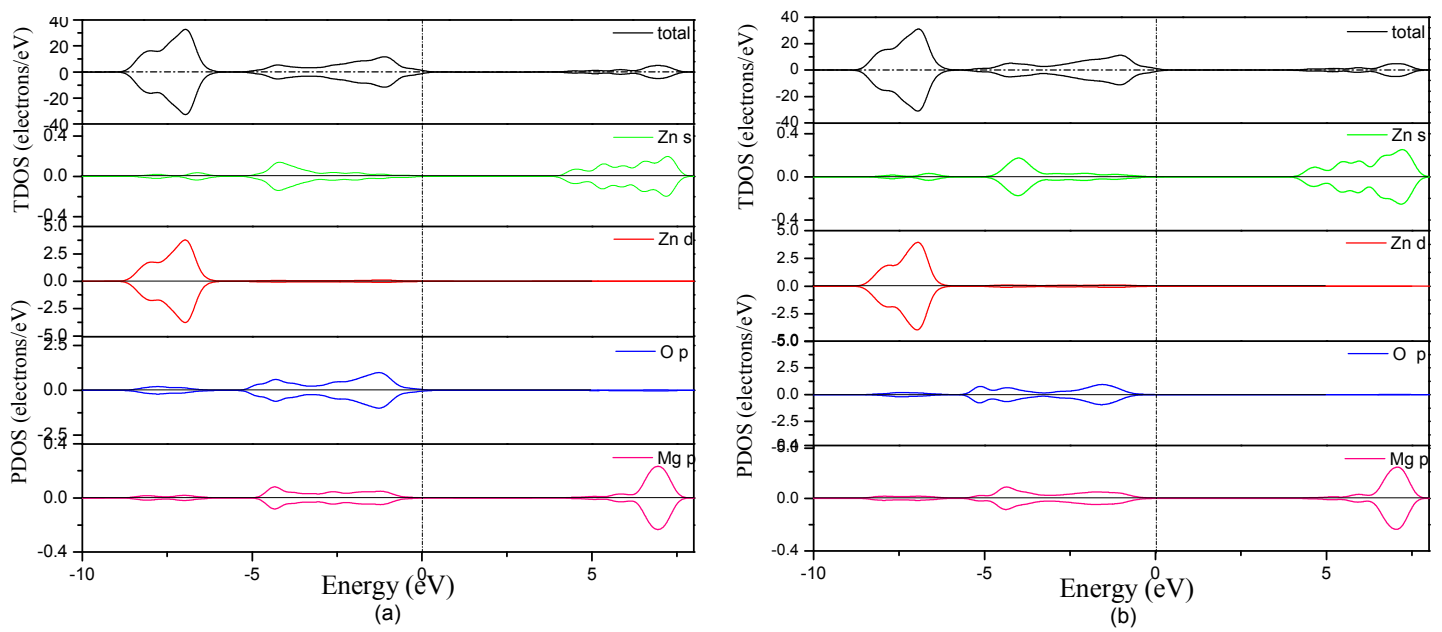

Figure 5. Cont. 

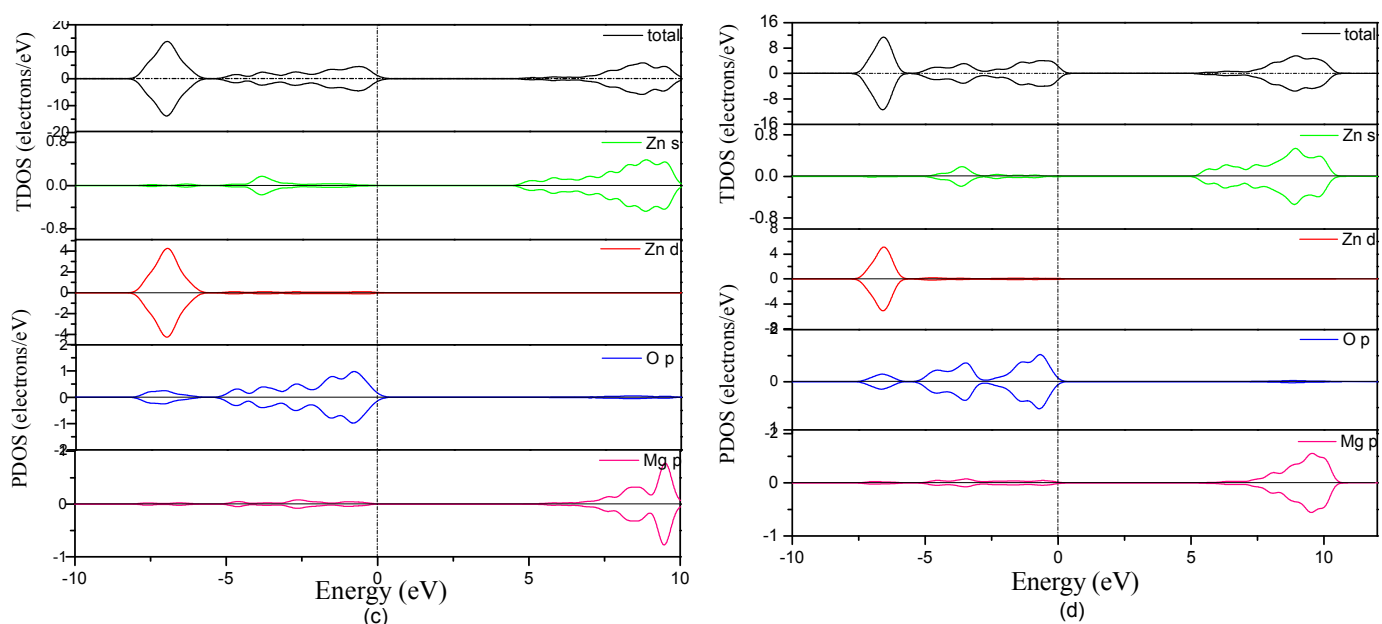

(d)
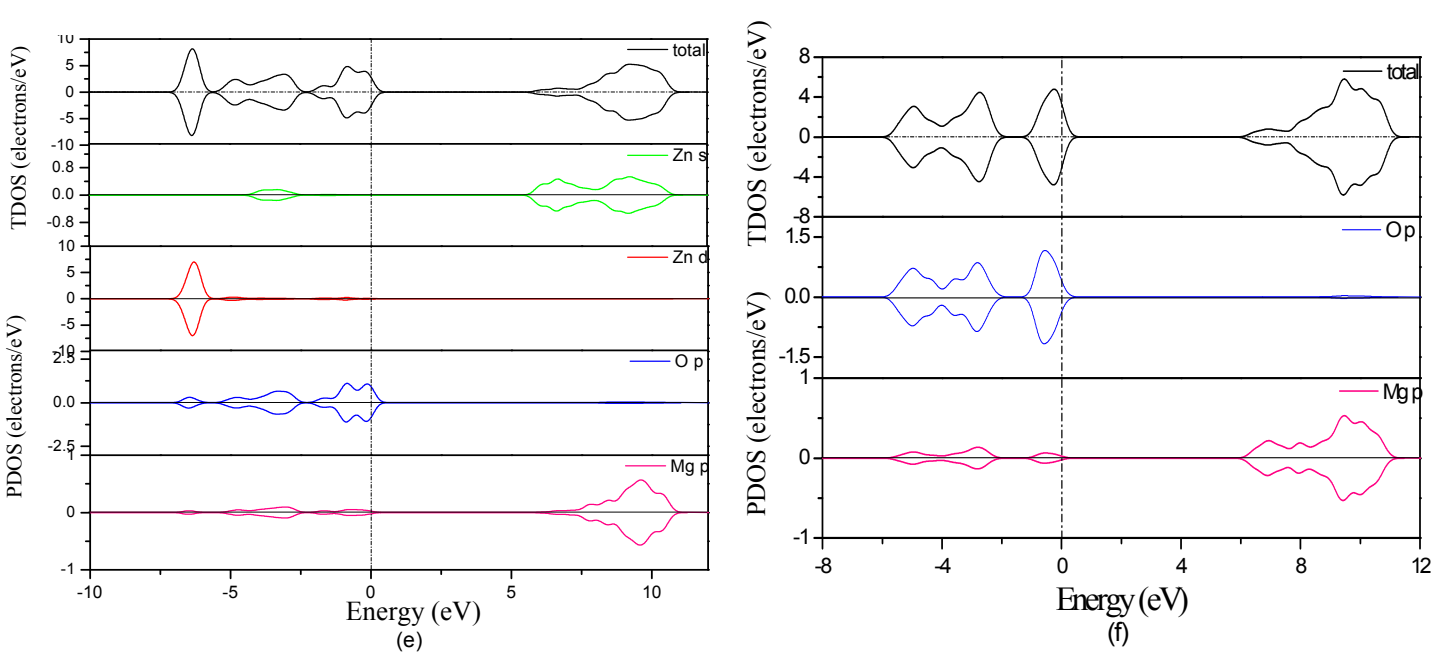

Figure 5. The total and partial DOS of $\mathrm{Mg}_{x} \mathrm{Zn}_{1-x} \mathrm{O}$ monolayer (a) $x=0.0625$; (b) $x=0.125$; (c) $x=0.25$; (d) $x=0.5$; (e) $x=0.75$; (f) $x=1$.

\subsection{Optical Properties of $\mathrm{MgZnO}$ Monolayer}

In general, the optical properties of semiconductor are closely related to their electronic structures and are of great importance to its application. Thus, we investigate the optical properties of $\mathrm{MgZnO}$ monolayer. The imaginary part $\varepsilon_{2}(\omega)$ of the dielectric function can be calculated from the momentum matrix elements between the occupied and unoccupied wave functions and the real part $\varepsilon_{1}(\omega)$ of the dielectric function can be evaluated from the imaginary part by the Kramer-Kronig relationship [48]. The absorption coefficient can then be obtained from $\varepsilon_{1}(\omega)$ and $\varepsilon_{2}(\omega)$. It is known that the imaginary part $\varepsilon_{2}(\omega)$ of the dielectric function is very important for any materials, thus for $\mathrm{MgZnO}$ monolayer are presented in Figure 6. It can be seen that there are three main peaks in for $\mathrm{MgZnO}$ monolayer with different $\mathrm{Mg}$ concentrations. In the case of pristine $\mathrm{ZnO}$ monolayer, the first peak at $4 \mathrm{eV}$ should mainly be caused by the transition between $\mathrm{O} 2 p$ states in the highest valence band and $\mathrm{Zn} 4 s$ states in the lowest conduction band, which is related to the direct band gap. The second peak at $8 \mathrm{eV}$ can be due to the transition between the $\mathrm{Zn} 3 d$ and $\mathrm{O} 2 p$ states. The weak peak at $14 \mathrm{eV}$ is mainly derived from the transition between the $\mathrm{Zn} 3 d$ and $\mathrm{O} 2 s$ states. The main effect of $\mathrm{Mg}$ doping lies in that the first peak due to the optical transition between the $\mathrm{Zn} 4 s$ and $\mathrm{O} 2 p$ states obviously shifts toward the high energy side with increasing $\mathrm{Mg}$ concentration, indicating that the band gap is increasing. Moreover, the strength of the first peak obviously decreases with the increase of $\mathrm{Mg}$ concentration. This is due to that the increase of $\mathrm{Mg}$ concentration corresponds to decrease of $\mathrm{Zn} 4 s$ states, resulting in 
the decrease of transition between the VBM and CBM. Furthermore, we have calculated the absorption coefficient of pristine $\mathrm{ZnO}$ monolayer and $\mathrm{MgZnO}$ monolayer, as shown in Figure 7. The changes of line shapes, energy positions, and strengths of the peaks of absorption spectrums with the increasing $\mathrm{Mg}$ concentration are similar to those of the imaginary part of the dielectric function. Particularly, it is worth noting that compared to pristine $\mathrm{ZnO}$ monolayer, the optical absorption edge of $\mathrm{MgZnO}$ monolayer has a clear blue-shift to a shorter wavelength region with increasing $\mathrm{Mg}$ concentration, which may have potential application for designing ultraviolet optoelectronic devices. The blue-shift of the absorption edge could be ascribed to the increase of band gap induced by $\mathrm{Mg}$ incorporation.

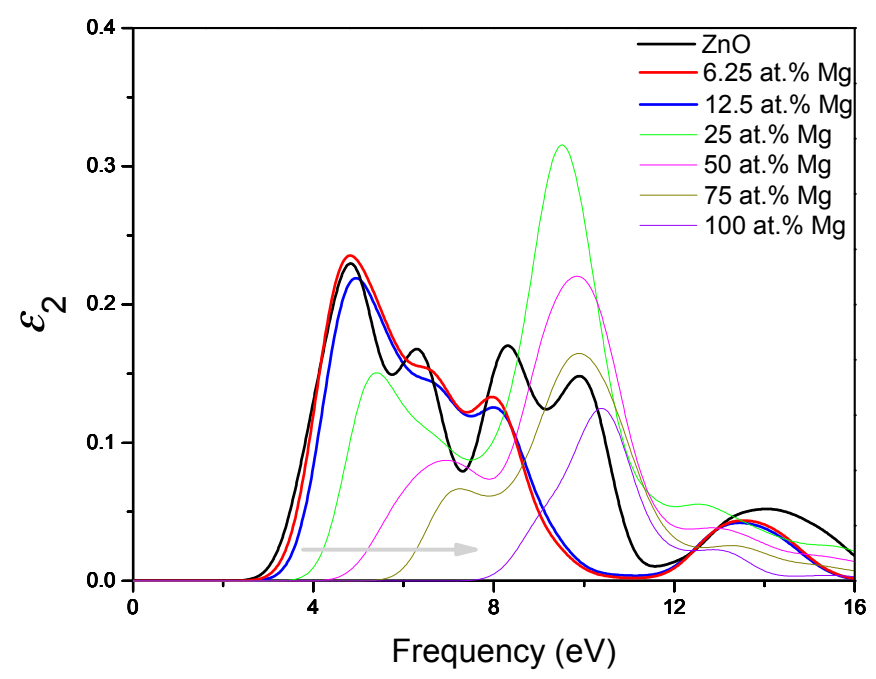

Figure 6. The imaginary part of dielectric function of $\mathrm{MgZnO}$ monolayer.

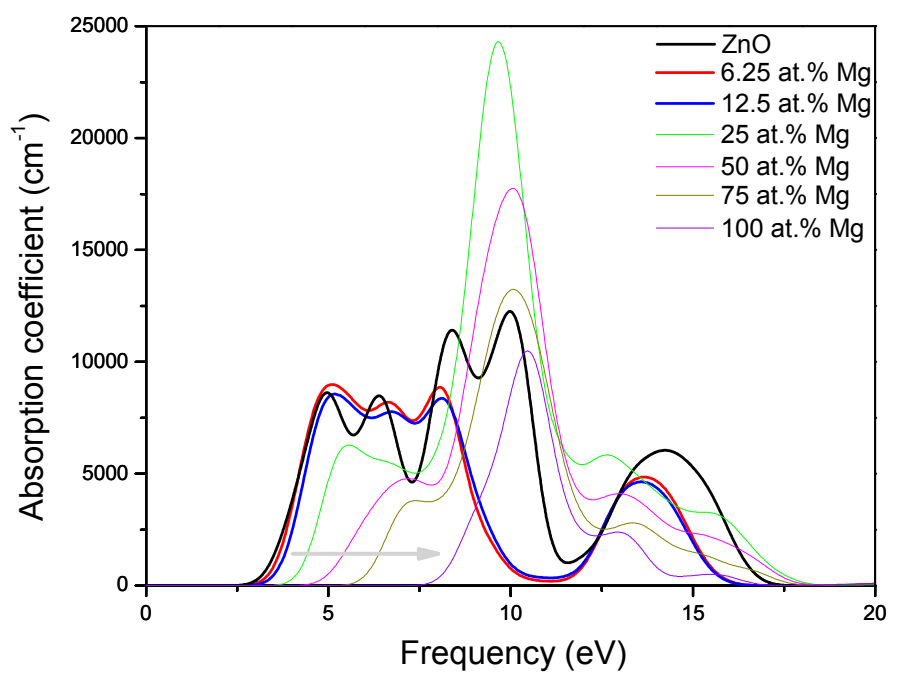

Figure 7. The absorption coefficient of $\mathrm{MgZnO}$ monolayer.

\section{Conclusions}

In conclusion, we report for the first time the first-principles investigations of phase stability, electronic structure, and optical properties of $\mathrm{MgZnO}$ monolayer. It is found that the phase segregation occurred in bulk system has not been observed in the monolayer due to size effect. $\mathrm{MgZnO}$ monolayer keeps the graphene-like structure with various $\mathrm{Mg}$ concentrations. Interestingly, $\mathrm{MgZnO}$ monolayer exhibits interesting tuning of electronic structure and optical properties with $\mathrm{Mg}$ concentration. The band gap increases with increasing Mg concentration. Particularly, a direct to indirect band 
gap transition is observed for $\mathrm{ZnMgO}$ monolayer when $\mathrm{Mg}$ concentration is higher than 75 at $\%$. Furthermore, we also found that $\mathrm{Mg}$ doping leads to a blue shift of the optical absorption peaks. These results may provide guidance for the potential application of $\mathrm{MgZnO}$ monolayer in ultraviolet optoelectronic devices at nanoscale.

Acknowledgments: The authors acknowledge the support of the National Natural Science Foundation of China (Grant Nos. 51471064, 51301054 and 51677044); the Program for New Century Excellent Talents (Grant No. 1253-NCET-009); and Program for Youth Academic Backbone in Heilongjiang Provincial University (Grant No. 1251G022).

Author Contributions: Changlong Tan conceived and designed the experiments; Changlong Tan and Dan Sun performed the experiments; Changlong Tan, Dan Sun, and Xiaohua Tian analyzed the data; Changlong Tan, Dan Sun, Xiaohua Tian, and Yuewu Huang wrote the paper.

Conflicts of Interest: The authors declare no conflict of interest.

\section{References}

1. Xu, M.S.; Liang, T.; Shi, M.M.; Chen, H.Z. Graphene-like two-dimensional materials. Chem. Rev. 2013, 113, 3766-3798. [CrossRef] [PubMed]

2. Ozgur, U.; Alivov, Y.I.; Liu, C.; Teke, A.; Reshchikov, M.A.; Dogan, S.; Avrutin, V.; Cho, S.J.; Morkoc, H. A comprehensive review of $\mathrm{ZnO}$ materials and devices. J. Appl. Phys. 2005, 98, 041301. [CrossRef]

3. Law, M.; Greene, L.E.; Johnson, J.C.; Saykally, R.; Yang, P.D. Nanowire dye-sensitized solar cells. Nat. Mater. 2005, 4, 455-459. [CrossRef] [PubMed]

4. Schmidt-Mende, L.; MacManus-Driscoll, J.L. ZnO-nanostructures, defects, and devices. Mater. Today 2007, 10, 40-48. [CrossRef]

5. Wang, Z.L. ZnO nanowire and nanobelt platform for nanotechnology. Mater. Sci. Eng. R 2009, 64, 33-71. [CrossRef]

6. Freeman, C.L.; Claeyssens, F.; Allan, N.L. Graphitic nanofilms as precursors to wurtzite films: Theory. Phys. Rev. Lett. 2006, 96, 066102. [CrossRef] [PubMed]

7. Tusche, C.; Meyerheim, H.L.; Kirschner, J. Observation of depolarized $\mathrm{ZnO}(0001)$ monolayers: Formation of unreconstructed planar sheets. Phys. Rev. Lett. 2007, 99, 026102. [CrossRef] [PubMed]

8. Weirum, G.; Barcaro, G.; Fortunelli, A.; Weber, F.; Schennach, R.; Surnev, S.; Netzer, F.P. Growth and Surface Structure of Zinc Oxide Layers on a Pd(111) Surface. J. Phys. Chem. C 2010, 114, 15432-15439. [CrossRef]

9. Quang, H.T.; Bachmatiuk, A.; Dianat, A.; Ortmann, F.; Zhao, J.; Warner, J.H.; Eckert, J.; Cunniberti, G.; Rummeli, M.H. In situ observations of free-standing graphene-like mono- and bilayer $\mathrm{ZnO}$ membranes. ACS Nano 2015, 9, 11408-11413. [CrossRef] [PubMed]

10. Lee, J.; Sorescu, D.C.; Deng, X.Y. Tunable lattice constant and band gap of single- and few-layer ZnO. J. Phys. Chem. Lett. 2016, 7, 1335-1340. [CrossRef] [PubMed]

11. Sahoo, T.; Nayak, S.K.; Chelliah, P.; Raht, M.K.; Parida, B. Observations of two-dimensional monolayer zinc oxide. Mater. Res. Bull. 2016, 75, 134-138. [CrossRef]

12. Schmidt, T.M.; MiWa, R.H.; Fazzio, A. Ferromagnetic coupling in a Co-doped graphenelike ZnO sheet. Phys. Rev. B 2010, 81, 195413. [CrossRef]

13. Guo, H.Y.; Zhao, Y.; Lu, N.; Kang, E.J.; Zeng, X.C.; Wu, X.J.; Yang, J.L. Tunable Magnetism in a Nonmetal-Substituted ZnO Monolayer: A First-Principles Study. J. Phys. Chem. C 2012, 116, 11336-11342. [CrossRef]

14. Tu, Z.C. First-principles study on physical properties of a single $\mathrm{ZnO}$ monolayer with graphene-like structure. J. Comput. Theor. Nanosci. 2010, 7, 1182-1186. [CrossRef]

15. He, A.L.; Wang, X.Q.; Lu, Y.H.; Feng, Y.P. Adsorption of an Mn atom on a $\mathrm{ZnO}$ sheet and nanotube: A density functional theory study. J. Phys. Condens. Matter 2010, 22, 175501. [CrossRef] [PubMed]

16. Tan, C.L.; Sun, D.; Xu, D.S.; Tian, X.H.; Huang, Y.W. Tuning electronic structure and optical properties of $\mathrm{ZnO}$ monolayer by Cd doping. Ceram. Int. 2016, 42, 10997-11002. [CrossRef]

17. Yang, J.; Wang, Y.Q.; Kong, J.H.; Yu, M.H.; Jin, H.Y. Syntheis of Mg-doped hierarchical ZnO nanostructures via hydrothermal method and their optical properties. J. Alloys Compd. 2016, 657, 261-267. [CrossRef] 
18. Schleife, A.; Eisenacher, M.; Rödl, C.; Fuchs, F.; Furthmüller, J.; Bechstedt, F. S Ab initio description of heterostructural alloys: Thermodynamic and structural properties of $\mathrm{Mg}_{x} \mathrm{Zn}_{1-x} \mathrm{O}$ and $\mathrm{Cd}_{x} \mathrm{Zn}_{1-x} \mathrm{O}$. Phys. Rev. B 2010, 81, 245210. [CrossRef]

19. Kasahara, Y.; Oshima, Y.; Falson, J.; Kozuka, Y.; Tsukazaki, A.; Kawasaki, M.; Iwasa, Y. Correlation-Enhanced Effective Mass of Two-Dimensional Electrons in $\mathrm{Mg}_{x} \mathrm{Zn}_{1-x} \mathrm{O} / \mathrm{ZnO}$ Heterostructures. Phys. Rev. Lett. 2012, 109, 246401. [CrossRef] [PubMed]

20. Shimada, K.; Takahashi, N.; Nakagawa, Y.; Hiramatsu, T.; Kato, H. Nonlinear characteristics of structural properties and spontaneous polarization in wurtzite $\mathrm{Mg}_{x} \mathrm{Zn}_{1-x} \mathrm{O}$ : A first-principles study. Phys. Rev. B 2013, 88, 075203. [CrossRef]

21. Ni, P.N.; Shan, C.X.; Li, B.H.; Shen, D.Z. High Mg-content wurtzite MgZnO alloys and their application in deep-ultraviolet light-emitters pumped by accelerated electrons. Appl. Phys. Lett. 2014, 104, 032107. [CrossRef]

22. Fan, X.F.; Sun, H.D.; Shen, Z.X.; Kuo, J.L.; Lu, Y.M. A first-principle analysis on the phase stabilities, chemical bonds and band gaps of wurtzite structure $\mathrm{A}_{x} \mathrm{Zn}_{1-x} \mathrm{O}$ alloys $(\mathrm{A}=\mathrm{Ca}, \mathrm{Cd}, \mathrm{Mg})$. J. Phys. Condens. Matter 2008, 20, 235221. [CrossRef] [PubMed]

23. Song, J.Z.; Kulinich, S.A.; Yan, J.; Li, Z.G.; He, J.P.; Kan, C.X.; Zeng, H.B. Epitaxial ZnO nanowire-on-nanoplate structures as efficient and transferable field emitters. Adv. Mater. 2013, 25, 5750. [CrossRef] [PubMed]

24. Ohtomo, A.; Tamura, K.; Kawasaki, M.; Makino, T.; Segawa, Y.; Tang, Z.K.; Wong, G.K.L.; Matsumoto, Y.; Koinuma, H. Room-temperature stimulated emission of excitons in $\mathrm{ZnO} /(\mathrm{Mg}, \mathrm{Zn}) \mathrm{O}$ superlattices. Appl. Phys. Lett. 2000, 77, 2204. [CrossRef]

25. Makino, T.; Segawa, Y.; Kawasaki, M.; Koinuma, H. Optical properties of excitons in ZnO-based quantum well heterostructures. Semicond. Sci. Technol. 2005, 20, S78. [CrossRef]

26. Sun, J.W.; Zhang, B.P. Well-width dependence of exciton-longitudinal-optical- phonon coupling in $\mathrm{MgZnO/ZnO} \mathrm{single} \mathrm{quantum} \mathrm{wells.} \mathrm{Nanotechnology} \mathrm{2008,} \mathrm{19,} \mathrm{485401.} \mathrm{[CrossRef]} \mathrm{[PubMed]}$

27. Gu, X.Q.; Zhu, L.P.; Ye, Z.Z.; He, H.P.; Zhang, Y.Z.; Huang, F.; Qiu, M.X.; Zeng, Y.J.; Liu, F.; Jaeger, W. Room-temperature photoluminescence from $\mathrm{ZnO} / \mathrm{ZnMgOZnO} / \mathrm{ZnMgO}$ multiple quantum wells grown on Si(111) substrates. Appl. Phys. Lett. 2007, 91, 022103. [CrossRef]

28. Makino, T.; Segawa, Y.; Kawasaki, M.; Ohtomo, A.; Shiroki, R.; Tamura, K.; Yasuda, T.; Koinuma, H. Band gap engineering based on $\mathrm{Mg}_{x} \mathrm{Zn}_{1-x} \mathrm{O}$ and $\mathrm{Cd}_{y} \mathrm{Zn}_{1-y} \mathrm{O}$ ternary alloy films. Appl. Phys. Lett. 2001, 78, 1237-1240. [CrossRef]

29. Yang, W.; Hullavarad, S.S.; Nagaraj, B.; Takeuchi, I.; Sharma, R.P.; Venkatesan, T.; Vispute, R.D.; Shen, H. Compositionally-tuned epitaxial cubic $\mathrm{Mg}_{x} \mathrm{Zn}_{1-x} \mathrm{O}$ on $\mathrm{Si}(100)$ for deep ultraviolet photodetectors. Appl. Phys. Lett. 2003, 82, 3424-3427. [CrossRef]

30. Yang, H.; Li, Y.; Norton, D.P.; Pearton, S.J.; Jung, S.; Ren, F.; Boatner, L.A. Characteristics of unannealed $\mathrm{ZnMgO} / \mathrm{ZnO}$ p-n junctions on bulk (100) ZnO substrates. Appl. Phys. Lett. 2005, 86, 172103-172106. [CrossRef]

31. Zhao, D.; Liu, Y.; Shen, D.; Lu, Y.; Zhang, J.; Fan, X.J. Structural and optical properties of $\mathrm{Mg}_{x} \mathrm{Zn}_{1-x} \mathrm{O}$ thin films prepared by the sol-gel method. J. Cryst. Growth 2002, 234, 427-430. [CrossRef]

32. Wang, Y.S.; Thomas, P.J.; O'Brien, P. Optical properties of $\mathrm{ZnO}$ nanocrystals doped with $\mathrm{Cd}, \mathrm{Mg}, \mathrm{Mn}$, and Fe ions. J. Phys. Chem. B 2006, 110, 21412. [CrossRef] [PubMed]

33. Sasa, S.; Ozaki, M.; Koike, K.; Yano, M.; Inoue, M. High-performance ZnO/ZnMgO field-effect transistors using a hetero-metal-insulator-semiconductor structure. Appl. Phys. Lett. 2006, 89, 53502-53505. [CrossRef]

34. Ohtomo, A.; Kawasaki, M.; Ohkubo, I.; Koinuma, H.; Yasuda, T.; Segawa, Y. Structure and optical properties of $\mathrm{ZnO} / \mathrm{Mg} 0.2 \mathrm{Zn} 0.8 \mathrm{O}$ superlattices. Appl. Phys. Lett. 1999, 75, 980-983. [CrossRef]

35. Choopun, S.; Vispute, R.D.; Yang, W.; Sharma, W.R.P.; Venkatesan, T.; Shen, H. Realization of band gap above $5.0 \mathrm{eV}$ in metastable cubic-phase $\mathrm{Mg}_{x} \mathrm{Zn}_{1-x} \mathrm{O}$ alloy films. Appl. Phys. Lett. 2002, 80, 1529-1532. [CrossRef]

36. Yin, Z.G.; Zheng, Q.D.; Chen, S.C.; Cai, D.D.; Ma, Y.L. Controllable ZnMgO electron-transporting layers for long-term stable organic solar cells with 8.06\% efficiency after one-year storage. Adv. Energy Mater. 2016, 6, 1501493. [CrossRef]

37. Sha, X.J.; Tian, F.B.; Li, D.; Duan, D.F.; Chu, B.H.; Liu, Y.X.; Liu, B.B.; Cui, T. Ab initio investigation of $\mathrm{CaO}-\mathrm{ZnO}$ alloys under high pressure. Sci. Rep. 2015, 5, 11003. [CrossRef] [PubMed]

38. Segall, M.; Lindan, P.; Probet, M.; Pickard, C.; Hasnip, P.; Clark, S.; Payne, M. First-principles simulation: Ideas, illustrations and the CASTEP code. J. Phys. Condens. Mater. 2002, 14, 2717. [CrossRef] 
39. Vanderbilt, D. Ultrasoft pseudopotentials in a generalized eigenvalue formalism. Phys. Rev. B 1990, 41, 7892-7895. [CrossRef]

40. Li, F.; Zhang, C.W.; Zhao, M.W. Magnetic and optical properties of Cu-doped ZnO nanosheet: First-principles calculations. Physica E 2013, 53, 101-105. [CrossRef]

41. Zheng, F.B.; Zhang, C.W.; Wang, P.J.; Luan, H.X. First-principles prediction of the electronic and magnetic properties of nitrogen-doped ZnO nanosheets. Solid State Commun. 2012, 152, 1199-1202. [CrossRef]

42. Li, Y.L.; Zhao, X.; Fang, W.L. Structural, electronic, and optical properties of Ag-doped ZnO nanowires: First principles study. J. Phys. Chem. C 2011, 115, 3552-3557. [CrossRef]

43. Sun, Z.Q.; Liao, T.; Dou, Y.H.; Hwang, S.M.; Park, M.S.; Jiang, L.; Kim, J.H.; Dou, S.X. Generalized self-assembly of scalable two-dimensional transition metal oxide nanosheets. Nat. Commun. 2014, 5, 3813. [CrossRef] [PubMed]

44. Ong, S.P.; Chevrier, V.L.; Ceder, G. Comparison of small polaron migration and phase separation in olivine $\mathrm{LiMnPO}_{4}$ and $\mathrm{LiFePO}_{4}$ using hybrid density functional theory. Phys. Rev. B 2011, 83, 075112. [CrossRef]

45. Zhang, P.H.; Capaz, R.B.; Cohen, M.L.; Louie, S.G. Theory of sodium ordering in $\mathrm{Na}_{x} \mathrm{CoO}_{2}$. Phys. Rev. $B$ 2005, 71, 153102. [CrossRef]

46. Zhang, Y.G.; He, H.Y.; Pan, B.C. Structural features and electronic properties of MgO nanosheets and nanobelts. J. Phys. Chem. C 2012, 116, 23130-23135. [CrossRef]

47. Wu, P.; Huang, M.; Cheng, W.J.; Tang, F.L. First-principles study of B, C, N and F doped graphene-like MgO monolayer. Physica E 2016, 81, 7-13. [CrossRef]

48. Chowdhury, R.; Adhikari, S.; Rees, P. Optcial properties of silicon doped ZnO. Physica B 2010, 405, $4763-4767$. [CrossRef]

(C) 2016 by the authors; licensee MDPI, Basel, Switzerland. This article is an open access article distributed under the terms and conditions of the Creative Commons Attribution (CC-BY) license (http://creativecommons.org/licenses/by/4.0/). 